\title{
JURISDIÇÃO DEMOCRÁTICA COMO INSTRUMENTO DE GARANTIA DA (RE) AFIRMAÇÃO DO DIREITO FUNDAMENTAL SOCIAL DO IDOSO AO BENEFÍCIO ASSISTENCIAL
}

\author{
DEMOCRATIC JURISDICTION TO GUARANTEE INSTRUMENT OF (RE) \\ AFFIRMATION OF FUNDAMENTAL SOCIAL RIGHTS OF THE ELDERLY TO \\ CARE BENEFIT
}

${ }^{1}$ Kaira Cristina da Silva

\section{RESUMO}

A presente pesquisa tem como objeto analisar a importância da jurisdição democrática como instrumento de garantia da (re)afirmação do direito fundamental social do idoso ao benefício assistencial. A proteção assistencial do idoso é de grande relevância, devido ao aumento considerável na faixa etária da população, bem como a necessidade de se promover condições mínimas de vida para as pessoas vulneráveis que se encontram em situação de desigualdade social e econômica. Para a realização desta pesquisa utilizou-se o Método Indutivo. Foram acionadas as técnicas do Referente, da Categoria, do Conceito Operacional e da Pesquisa Bibliográfica.

Palavras-chave: Idoso vulnerável, Benefício assistencial, Jurisdição democrática

\begin{abstract}
This research aims to analyze the importance of democratic jurisdiction to guarantee instrument of (re) affirmation of fundamental social rights of the elderly to care benefit. The health care protection of the elderly is of great importance due to the considerable increase in the age group of the population and the need to promote minimum living conditions for vulnerable people who are in social and economic inequality situation. For this research we used the Inductive Method. Regarding the techniques, Category, Operational Concept and the Bibliographical Research they were triggered.
\end{abstract}

Keywords: Vulnerable elderly, Care benefit, Democratic jurisdiction

\footnotetext{
${ }^{1}$ Mestranda em Ciência Jurídica pelo Programa de Pós-Graduação Stricto Sensu em Ciência Jurídica da Universidade do Vale do Itajaí - UNIVALI, Santa Catarina (Brasil). E-mail: kairasilva@ outlook.com
} 


\section{INTRODUÇÃO}

A presente pesquisa tem como objeto analisar a importância da jurisdição democrática como instrumento de garantia da (re)afirmação do direito fundamental social do idoso ao benefício assistencial.

O direito fundamental social do idoso ao benefício assistencial possui uma função de grande relevância, pois além de proporcionar um patamar digno de vida à pessoa idosa em situação de vulnerabilidade, também contribui para a redução das desigualdades sociais, bem como para a erradicação da pobreza, ainda que neste último caso os resultados ocorram de forma gradativa.

No entanto, a Lei Orgânica da Assistência Social, política pública que define os critérios para a concessão do benefício assistencial ao idoso, estabelece requisitos objetivos que obstaculizam a efetividade deste benefício, sendo que não estão materialmente de acordo com a Constituição Federal de 1988. Portanto, questiona-se: Por que a jurisdição democrática é um importante instrumento de garantia da (re)afirmação do direito fundamental social do idoso ao benefício assistencial?

Os objetivos específicos do presente estudo consistem em: a) identificar o fundamento e conceito dos direitos fundamentais; b) compreender os direitos fundamentais sociais como direitos de igualdade; c) definir o direito do idoso ao benefício assistencial e os critérios para a concessão deste benefício; d) analisar a importância da jurisdição democrática como instrumento de (re)afirmação do direito fundamental social do idoso ao benefício assistencial, em um Estado Democrático de Direito cuja mola propulsora é o constitucionalismo contemporâneo.

Quanto à Metodologia empregada, registra-se que, na Fase de Investigação foi utilizado o Método Indutivo, na Fase de Tratamento de Dados o Método Cartesiano, e o Relatório dos Resultados expresso na presente pesquisa é composto na base lógica indutiva. Nas diversas fases da pesquisa são utilizadas as Técnicas do Referente, da Categoria, do Conceito Operacional, e da Pesquisa Bibliográfica. 


\section{O CONCEITO E OS FUNDAMENTOS DOS DIREITOS FUNDAMENTAIS}

A evolução dos direitos fundamentais se dá historicamente, de acordo com os conflitos que afligem a vida em sociedade em determinado tempo, e que impulsionam as transformações no cenário jurídico e social.

Peces-Barba explica que uma compreensão integral do fundamento e do conceito de direitos fundamentais é produzida com uma resposta adequada ao 'por que' e 'para que' dos direitos fundamentais, sendo que o por que consiste na pretensão moral justificada, e o para que se refere principalmente à recepção dessa pretensão moral no direito positivo.

A justiça intrínseca aos direitos humanos reside na sua concepção moral e sua força encontra-se no ordenamento jurídico em que está positivado. Portanto, não é possível uma compreensão integral do conceito e dos fundamentos dos direitos humanos, expressão esta utilizada por Peces-Barba, sem que a moralidade e a juridicidade sejam vislumbradas. Neste sentido, Garcia (2008, p. 198) ensina que:

Em primeiro lugar os direitos fundamentais devem ser, ou devem partir de uma pretensão moral justificada. Os direitos fundamentais devem ser uma pretensão moral que esteja justificada na dignidade da pessoa humana - seu pilar principal -, na igualdade, na liberdade e na solidariedade humana - seus outros três pilares de sustentação -. Dito em outras palavras os direitos fundamentais devem estar fundamentados em alguns valores básicos que foram se formando a partir da modernidade.

A fundamentação do direito consiste em duas dimensões, quais sejam sua historicidade e racionalidade. Já a função dos direitos consiste na sua positivação.

Peces-Barba afirma que somente a partir do trânsito à modernidade é possível falar de direitos fundamentais, sendo que esta passagem da Idade Média para a Moderna se dá em três níveis, os quais ele expressa que consistem na evolução da realidade social no que é relevante para entender o surgimento, a evolução, o desenvolvimento, e a possibilidade dos direitos; situação do pensamento quanto ao seu conceito, seu sentido e sua fundamentação, o que o referido autor chama de Filosofia dos Direitos Fundamentais (Filosofía de los Derechos Fundamentales); e por fim sua incorporação em normas de Direito positivo, tanto no plano constitucional como legal, jurisprudencial, etc., com a influência do poder capaz de produzir uma juridificação (PECES-BARBA, 1995, p. 115). 
A evolução dos direitos fundamentais é um processo dinâmico que permanece até os diais atuais, eis que a sociedade muda constantemente e os direitos devem acompanhar as mudanças sociais.

Peces-Barba estabelece as linhas de evolução dos direitos fundamentais, que consistem respectivamente no processo de positivação, generalização, internacionalização e especificação.

Sobre as referidas linhas de evolução dos direitos fundamentais Garcia (2008, p. 195) sintetiza:

\begin{abstract}
Resumidamente estes são: a) processo de positivação: a passagem da discussão filosófica ao Direito positivo (primeira geração, direitos de liberdade); b) processo de generalização: significa a extensão do reconhecimento e proteção dos direitos de uma classe a todos os membros de uma comunidade como conseqüência da luta pela igualdade real (direitos sociais ou de segunda geração); c) processo de, internacionalização: ainda em fase embrionária, de difícil realização prática e que implica na tentativa de internacionalizar os direitos humanos e que ele esteja por cima das fronteiras e abarque toda a Comunidade Internacional; d) processo de especificação: pelo qual se considera a pessoa em situação concreta para atribuir-lhe direitos seja como titular de direitos como criança, idoso, como mulher, como consumidor, etc, ou como alvo de direitos como o de' um meio ambiente saudável ou à paz (direitos difusos ou de terceira geração).
\end{abstract}

No que se refere ao processo de positivação dos direitos fundamentais, ressalta-se que a moral é assumida pelo poder, e daí decorre a positivação, mas quando se sustenta que o poder é quem cria a moral (conforme ocorre no Estado absoluto), afasta-se de todo o processo de construção e evolução dos direitos fundamentais. Portanto, para Peces-Barba deve haver um equilíbrio entre os valores morais, o poder político e o Direito positivo (PECES-BARBA, 1995, p. 157).

Desta forma, somente é possível garantir e validade e eficácia dos direitos fundamentais, quando a pretensão justificada é positivada. Não se pode falar em direitos fundamentais quando a pretensão moral não está inserida no Direito positivo, eis que aí está se tratando apenas de um valor e não de um direito.

O processo de generalização consiste na afirmação de que os direitos fundamentais pertencem a todos, enfatiza-se que os direitos não pertencem apenas a um determinado grupo de pessoas, mas a todos os seres humanos. Conforme Peces-Barba, a democracia é o ponto de encontro entre o liberalismo e o socialismo (PECES-BARBA, 1995, p. 164).

Resulta do processo de generalização a marcha para os direitos que garantem ou possibilitam uma participação política igualitária, a configuração de uma nova geração de 
direitos fundamentais para assegurar a solidariedade e a igualdade, e a "desfundamentalização" do direito de propriedade (PECES-BARBA, 1995, p. 164).

Os grupos sociais democráticos passarão a ter direito de associação e de sufrágio, fato este que culminará em sua participação na formação dos órgãos públicos que exprimem a vontade estatal, incidindo no constitucionalismo como uma atuação positiva dos poderes públicos, acarretando a formulação dos direitos econômicos, sociais e culturais.

Quanto ao processo de internacionalização, destaca-se que a soberania é um obstáculo que se contrapõe à proteção dos direitos fundamentais, caso em que seria necessária a implementação de um poder político supranacional.

As três dimensões do processo de internacionalização são: a) a utilização de formas técnico-jurídicas do Direito internacional clássico pelos Estados; b) a conscientização da insuficiência da proteção estatal; as transformações experimentadas nas últimas décadas pelo Internacional, sendo o processo de desenvolvimento integral dos indivíduos e dos povos (PECES-BARBA, 1995, p. 178).

O processo de especificação dos direitos fundamentais, terminologia utilizada por Bobbio, conforme explica Peces-Barba, produz uma relação com os titulares dos direitos e com o seu conteúdo.

Trata-se de um processo em que se pressupõe que o titular do direito esteja em uma situação de fragilidade, seja ela física, psicológica ou cultural, e portanto, o conteúdo do seu direito está vinculado a superação desta situação.

Estas situações, resumidamente, decorrem de uma condição social ou cultural de pessoas que se encontram em situação de inferioridade nas relações sociais e que necessitam de uma proteção especial fundada na promoção da igualdade; de uma condição física que obriga a proteção especial fundada na solidariedade e na fraternidade; e de uma condição de vulnerabilidade em que a outra parte tem um papel preponderante, o que exige um equilíbrio através de uma proteção reforçada fundada na segurança jurídica, como por exemplo, os direitos do consumidor (PECES-BARBA, 1995, p. 182). 


\subsection{Caracterização dos direitos fundamentais sociais como direitos de igualdade}

A partir do século XVIII, o Estado passou a tutelar as liberdades do indivíduo, principalmente no que se refere à propriedade privada, que eram as necessidades demandadas naquele tempo pela sociedade burguesa (CRUZ, 2003, p. 89) ${ }^{1}$.

Neste período histórico, o Estado Liberal tem como pressuposto abster-se da intervenção na esfera privada do indivíduo. Esta época teve como marco o reconhecimento igualdade formal.

No entanto, a concepção de igualdade formal, "que orientou o movimento liberal em sua vertente jurídica", restou insuficiente, sendo que "foi ultrapassada pela necessidade de igualdade social como pressuposto para aquela igualdade, principalmente com a inclusão, no processo político, de outras classes sociais diferentes da burguesia” (CRUZ, 2003, p. 93).

Wolkmer (2003, p. 26) ensina que as necessidades sociais que demandaram a superação do Estado Liberal, “[...] possibilitaram a complexa experiência de uma estrutura que, por estar ainda em curso, assume diversas especificidades, cunhada por autores com as designações de Estado Social, [...] Estado Providência ou Assistencial (Welfare State), etc”.

Carbonell (CARBONELL; SALAZAR, 2005, p. 179) atenta para o fato de que no modelo de Estado social os poderes públicos deixam de ser vistos como inimigos dos direitos fundamentais, e passam a exercer, ao contrário, o papel de promotores desses direitos, sobretudo dos de caráter social.

Canotilho (1995, p. 206) acentua o dever de respeito pelo Estado de Direito Constitucional ao afirmar que:

aponta-se para um equilíbrio entre os dois conceitos - Estado de Direito e Estado Social -, pois a liberdade é inconcebível sem um elevado grau de solidariedade e de igualdade social, e, por outro lado, o progresso social, o desenvolvimento econômico e a proteção das classes mais desfavorecidas deve fundar-se no respeito pelo Estado de direito constitucional.

\footnotetext{
${ }^{1}$ Sobre o liberalismo, Cruz explica: "Corrente de pensamento que se consolidou a partir das revoluções burguesas do século XVIII, o liberalismo caracteriza-se por defender as maiores cotas possíveis de liberdade individual frente ao Estado, que deve procurar ser neutro. Postula tanto uma filosofia tolerante da vida como modelo social que conseguiu substituir o Antigo Regime e cujos conteúdos se constituíram em fundamento jurídico e político das constituições democráticas”. (CRUZ, 2003, p. 89)
} 
Na feição de Estado Democrático de Direito, é fundamental "a incorporação efetiva da questão da igualdade como um conteúdo próprio a ser buscado garantir através do asseguramento mínimo de condições mínimas de vida ao cidadão e à comunidade", o que significa considerar a lei como um instrumento de ação concreta do Estado, ensina Streck (2014, p. 47).

Segundo os ensinamentos de Bobbio (1997, p. 43), "A igualdade entendida como equalização dos diferentes é um ideal permanente e perene dos homens vivendo em sociedade. Toda superação dessa ou daquela discriminação é interpretada como uma etapa do progresso da civilização".

Assim, a Constituição expressa instrumentos garantidores dos direitos fundamentais como forma de superar a crise do Estado Social, e para facilitar a realização de seus objetivos, considerando-se esta função social como um plus normativo, extrai-se do entendimento de Streck (2014, p. 47-48).

\section{DIREITO FUNDAMENTAL SOCIAL DO IDOSO AO BENEFÍCIO ASSISTENCIAL}

O Estado tem como objetivo proporcionar o bem-estar e a justiça social, para tanto a Constituição da República Federativa do Brasil de 1988 estabelece direitos fundamentais sociais destinados a promover a proteção social, os quais integram a Seguridade Social², especificamente o direito à saúde, à previdência e à assistência social. São direitos fundamentais sem os quais o indivíduo não atinge um patamar digno de vida, e sua efetivação repercute em toda a sociedade.

A presente pesquisa trata especificamente ao direito do idoso ao benefício assistencial, afinal este ser humano merece uma atenção especial, principalmente quando não dispõe de meios para prover sua subsistência. Fato este que torna o idoso mais fragilizado perante a sociedade e que abala sua saúde física e psicológica, portanto a família, a sociedade e o Estado têm o dever de ampará-lo ${ }^{3}$ neste período da existência humana.

\footnotetext{
${ }^{2}$ Conforme o artigo 194 da CRFB/88 "A seguridade social compreende um conjunto integrado de ações de iniciativa dos Poderes Públicos e da sociedade, destinadas a assegurar os direitos relativos à saúde, à previdência e à assistência social". BRASIL. Constituição da República Federativa do Brasil de 1988. Diário Oficial da União, n. 191-A, 05 out. 1988. Disponível em: http://www.planalto.gov.br/ccivil_03/Constituicao/Constituicao.htm Acesso em: 16 Fev. 2013.

${ }^{3}$ A Constituição Federal de 1988 estabelece em seu artigo 230 que "A família, a sociedade e o Estado têm o dever de amparar as pessoas idosas, assegurando sua participação na comunidade, defendendo sua dignidade e bem-estar e garantindo-lhes o direito à vida". No mesmo sentido o Estatuto do Idoso em seu artigo $3^{\circ}$ preceitua que "É obrigação da família, da comunidade, da sociedade e do Poder Público assegurar ao idoso, com absoluta prioridade, a efetivação do direito à vida, à saúde, à alimentação, à educação, à cultura, ao esporte, ao lazer, ao trabalho, à cidadania, à liberdade, à dignidade, ao respeito e à convivência familiar e comunitária".
} 
O direito do idoso ao benefício assistencial consiste em um direito fundamental social assegurado pela Constituição Federal de 1988, o qual deve ser garantido e efetivado pelos Poderes Públicos, sendo inadmissível qualquer forma de restrição, tendo em vista que dele decorre o próprio direito à vida e à dignidade humana da pessoa idosa em situação de vulnerabilidade.

A Constituição da República Federativa do Brasil de 1988, em seu Título VIII, Capítulo II, Seção IV dispõe sobre a assistência social, que será prestada a quem dela necessitar, independentemente de contribuição à seguridade social. Trata-se de política pública não contributiva regulamentada pela Lei n. 8.742, de 07 de dezembro de 1993, que dispõe sobre a organização da assistência social e dá outras providências.

Martinez (1992, p. 99) conceitua a assistência social da seguinte maneira:

[...] conjunto de atividades particulares e estatais direcionadas para o atendimento dos hipossuficientes, consistindo os bens oferecidos em pequenos benefícios em dinheiro, assistência à saúde, fornecimento de alimentos e outras pequenas prestações. Não só complementa os serviços da Previdência Social, como a amplia, em razão da natureza da clientela e das necessidades providas.

Simões (1967, p. 43) menciona que "assistência é a forma de solidariedade, incondicionada a qualquer contraprestação, equivalente a retribuição ou preço, destinada a socorrer, ajudar ou amparar o homem em suas necessidades vitais", nos termos do art. $1^{\circ}$ da Lei Orgânica da Assistência Social (Lei 8.742/93) ${ }^{4}$.

No que se refere à proteção assistencial do idoso na legislação brasileira, a Constituição da República Federativa do Brasil de 1988 estabelece em seu artigo 203, inciso I, que a assistência social tem como um de seus objetivos a proteção à velhice, assegurando, no inciso $\mathrm{V}$ do referido artigo, o benefício assistencial, que consiste na "garantia de um salário mínimo de benefício mensal à pessoa portadora de deficiência e ao idoso que comprovem não possuir meios de prover à própria manutenção ou de tê-la provida por sua família, conforme dispuser a lei”.

O benefício de prestação continuada da assistência social também está previsto no art. 20, da Lei Orgânica da Assistência Social, bem como no artigo 34, caput, do Estatuto do Idoso (Lei $\mathrm{n}^{\circ} 10.741$, de 01 de outubro de 2003).

\footnotetext{
${ }^{4}$ Art. $1^{\text {o }}$. Lei n. 8.742/93. A assistência social, direito do cidadão e dever do Estado, é Política de Seguridade Social não contributiva, que provê os mínimos sociais, realizada através de um conjunto integrado de ações de iniciativa pública e da sociedade para garantir as necessidades básicas. BRASIL. Lei 8.742 de 7 de dezembro de 1993. Dispõe sobre a organização da assistência social e dá outras providências. Disponível em: http://www.planalto.gov.br/ccivil_03/leis/18742.htm Acesso em: 18 fev. 2016.
} 
O benefício assistencial garante ao idoso vulnerável, condições básicas para a sua subsistência, quando da sua miserabilidade não possui renda sequer para comprar alimentos. Muitas vezes perecendo por ocasião de doenças decorrentes da falta de alimentação adequada ou pela insuficiência de recursos financeiros para adquirir medicamentos indisponibilizados gratuitamente pelo Estado. Situação esta que transgride a própria dignidade da pessoa humana, preceito fundamental em um Estado Democrático de Direito.

Não obstante, o benefício de prestação continuada da assistência social significa uma pequena contribuição para a erradicação da pobreza ${ }^{5}$, apesar de não ser o suficiente para suprir as demandas sociais (BORTOLETO, 2000, p. 40-47).

Ocorre que existem situações que ensejam a concessão do benefício assistencial ao idoso, porém não são tuteladas de forma adequada pela legislação brasileira.

Tais situações envolvem os requisitos necessários para a concessão do referido benefício, dentre as quais destaca-se o critério objetivo para aferição da miserabilidade do idoso que pleiteia o benefício assistencial; bem como a previsão legal constante no parágrafo único, do artigo 34, do Estatuto do Idoso, conforme será abordado sucessivamente.

\subsection{Do requisito renda per capita inferior a $1 / 4$ do salário mínimo}

O parágrafo $3^{\circ}$, do art. 20, da Lei Orgânica da Assistência Social estabelece como requisito para aferir a condição de miserabilidade do idoso, a renda familiar per capita inferior a um quarto do salário mínimo. Este requisito tem sido discutido frequentemente no âmbito do Poder Judiciário e, com isso, tem originado relevante evolução na concessão do benefício assistencial por intermédio da jurisdição.

No âmbito administrativo o indeferimento do benefício assistencial tem prejudicado significativamente os idosos que se encontram em situação de vulnerabilidade, pois o Instituto Nacional do Seguro Social aplica taxativamente o requisito do $\S 3^{\circ}$, do art. 20, da Lei Orgânica da Assistência Social.

Isto se dá porque os servidores públicos que atuam na referida autarquia têm o dever de fundamentar suas decisões exclusivamente nos ditames legais, devido à estrita observância ao princípio da legalidade que vigora na Administração Pública.

\footnotetext{
${ }^{5}$ A erradicação da pobreza é um dos objetivos fundamentais da República Federativa do Brasil, previsto no artigo $3^{\circ}$, inciso III da Constituição Federal de 1988.
} 
Numa primeira análise acerca do requisito renda per capita familiar inferior a um quarto do salário mínimo, conforme o julgamento da Ação Direta de Inconstitucionalidade 1232/DF ${ }^{6}$, o Supremo Tribunal Federal declarou constitucional o dispositivo de lei que impõe tal requisito, porém não o fixou como único critério para a concessão do benefício assistencial, sendo admitida a análise de outros meios que comprovem o verdadeiro estado de vulnerabilidade do idoso.

Desde que comprovado o requisito idade para fins de concessão do benefício assistencial ao idoso, ainda que a renda mensal per capita do grupo familiar seja superior a $1 / 4$ (um quarto) do salário mínimo, poderão ser analisadas outras situações que comprovem a hipossuficiência do idoso e de sua família. Conforme defende Sanctis Júnior (2011):

[...] ao interpretar os requisitos que regem a concessão de benefícios assistenciais, o Poder Judiciário levaria em conta, além dos pressupostos de ordem objetiva, outras circunstâncias de ordem subjetiva trazidas ao processo, e que autorizem a conclusão de que aquela pessoa se encontra em um estado de miserabilidade, e que não pode ter o seu sustento amparado por si ou pessoa de sua família.

O Superior Tribunal de Justiça já havia adotado o referido entendimento ao afirmar que o critério objetivo para constatar a condição de miserabilidade do idoso que pleiteia o benefício assistencial não restringe a possibilidade de sua concessão e não dispensa a análise de outros elementos que comprovem tal condição ${ }^{7}$.

Sobre as decisões dos magistrados quanto ao critério objetivo de aferição da miserabilidade do idoso para fins de concessão do benefício assistencial, Uvo explica que:

Esse fato, porém, não impede que os Juízes avaliem no caso concreto a efetiva pobreza e necessidade da pessoa a ser amparada pelo benefício, quando, por exemplo, gasta muito com remédios ou possui outras despesas relevantes que comprometem a sua subsistência digna, ainda que sua renda mensal seja superior ao valor de um quarto do salário mínimo.

\footnotetext{
${ }^{6}$ CONSTITUCIONAL. IMPUGNA DISPOSITIVO DE LEI FEDERAL QUE ESTABELECE O CRITÉRIO PARA RECEBER O BENEFÍCIO DO INCISO V DO ART. 203, DA CF. INEXISTE A RESTRIÇÃO ALEGADA EM FACE AO PRÓPRIO DISPOSITIVO CONSTITUCIONAL QUE REPORTA À LEI PARA FIXAR OS CRITÉRIOS DE GARANTIA DO BENEFÍCIO DE SALÁRIO MÍNIMO À PESSOA PORTADORA DE DEFICIÊNCIA FÍSICA E AO IDOSO. ESTA LEI TRAZ HIPÓTESE OBJETIVA DE PRESTAÇÃO ASSISTENCIAL DO ESTADO. AÇÃO JULGADA IMPROCEDENTE. BRASIL, Supremo Tribunal Federal. ADIn 1.232-1. Distrito Federal. Relator: Ilmar Galvão. Data de Julgamento: 26/08/1998. Tribunal Pleno. Data de Publicação: DJ 01/06/2001. Disponível em: http://redir.stf.jus.br/paginadorpub/paginador.jsp?docTP=AC\&docID=346917 Acesso em: 16 fev. 2016.

${ }^{7}$ AgRg no AREsp 149082/RJ, Rel. Min. Castro Meira, Segunda Turma, Julgado em: 11/12/2012, DJe: 04/02/2013; AgRg no REsp 1351525 / SP, Rel. Min. Mauro Campbell Marques; Segunda Turma, Julgado em: 06/12/2012, DJe: 12/12/2012; AgRg no AREsp 244883/SP, Rel. Min. Humberto Martins, Segunda Turma, Julgado em: 27/11/2012, DJe: 04/12/2012.
} 
No mesmo sentido, Castro e Lazzari (2012, p. 718) alertam:

Os critérios para aferição do requisito econômico são polêmicos e segundo orientação do STJ o magistrado não está sujeito a um sistema de tarifação legal de provas, motivo pelo qual a delimitação do valor da renda familiar per capita não deve ser tida como único meio de prova da condição de miserabilidade do requerente.

Com isso, tornou-se possível que o Poder Judiciário analise as situações fáticas apresentadas em cada processo como forma de comprovação da situação de pobreza do idoso e de seu grupo familiar.

A interpretação conforme as peculiaridades de cada situação, é de extrema importância para a análise dos casos que versam sobre o benefício assistencial, pois o idoso vulnerável se mantém na incerteza de estar vivo quando por si só, ou até mesmo com a ajuda de sua família, não dispõe de meios suficientes para prover sua manutenção.

\subsection{Do parágrafo único, do art. 34, do Estatuto do Idoso}

Há também que destacar como uma situação que enseja a concessão do benefício assistencial ao idoso a possibilidade de exclusão de benefício previdenciário de valor mínimo do cálculo da renda per capita do grupo familiar.

Segundo o parágrafo único do art. 34, do Estatuto do Idoso, o benefício assistencial poderá ser concedido a mais de um idoso do mesmo grupo familiar, pois o valor do benefício de prestação continuada da assistência social não integra o cálculo da renda familiar per capita ${ }^{8}$.

Sendo assim, se o benefício assistencial que é concedido ao idoso independentemente de contribuição à seguridade social não integra o cálculo, haveria flagrante descumprimento ao princípio constitucional da igualdade se o benefício de valor mínimo percebido por aquele que contribuiu para a previdência durante todo o período necessário não fosse excluído do cálculo da renda per capita do grupo familiar.

\footnotetext{
8 Art. 34. Lei n. 10.741/03. Aos idosos, a partir de 65 (sessenta e cinco) anos, que não possuam meios para prover sua subsistência, nem de tê-la provida por sua família, é assegurado o benefício mensal de 1 (um) salário-mínimo, nos termos da Lei Orgânica da Assistência Social - Loas. Parágrafo único. O benefício já concedido a qualquer membro da família nos termos do caput não será computado para os fins do cálculo da renda familiar per capita a que se refere a Loas.
} 
Sobre a possibilidade da aplicação do parágrafo único, do art. 34, do Estatuto do Idoso, com relação a outros benefícios de valor mínimo além do benefício assistencial, Vianna (2010, p. 37) menciona que:

[...] O raciocínio adotado é o seguinte: se a percepção da LOAS independe de contribuição, porque se trata de benefício assistencial, com maior razão ainda deveria excluir-se benefício previdenciário de valor mínimo, para o qual exigiu-se contribuição do segurado, pois, do contrário, estar-se-ia beneficiando aquele que não contribuiu para o sistema de seguridade social em detrimento daquele que contribuiu.

Esta situação requer do Poder Judiciário, uma interpretação justa e equânime da lei, tendo em vista que o comando normativo muitas vezes não é suficiente para atender aos anseios sociais, principalmente quando se trata de casos relacionados a idosos vulneráveis.

\section{A JURISDIÇÃO DEMOCRÁTICA COMO INSTRUMENTO DE GARANTIA DA (RE)AFIRMAÇÃO DA PROTEÇÃO ASSISTENCIAL DO IDOSO VULNERÁVEL}

O jusfilósofo italiano Luigi Ferrajoli ensina que as garantias jurisdicionais são secundárias, já que as primárias ou substanciais consistem nas obrigações ou proibições que correspondem aos direitos subjetivos garantidos. As garantias jurisdicionais são, portanto, "as obrigações, por parte dos órgãos judiciais, de aplicar a sanção ou declarar a nulidade quando se constatem, no primeiro caso, atos ilícitos e, no segundo, atos inválidos que violem os direitos subjetivos e, com eles, suas correspondentes garantias primárias". (FERRAJOLI, 2010, p. 64)

Pisarello classifica as garantias jurisdicionais em ordinárias e especiais. As garantias jurisdicionais ordinárias, são confiadas aos tribunais divididos em diferentes ordens (civis, penais, trabalhistas, contencioso-administrativo) com capacidade para prevenir, controlar ou sancionar vulnerações de direitos provenientes de órgãos administrativos ou de particulares (PISARELLO, 2007, p. 120-121)

Já as garantias jurisdicionais especiais geralmente são confiadas aos tribunais superiores ou especificamente constitucionais, e seu objetivo, basicamente, é estabelecer mecanismos de controle e reparação naqueles casos em que as garantias jurisdicionais ordinárias tem resultado insuficientes ou nos que a vulneração dos direitos pode atribuir-se as ações ou omissões do próprio legislador. (PISARELLO, 2007, p. 121) 
Os critérios para a concessão do benefício são incompatíveis com um sistema jurídico cujo paradigma é o constitucionalismo contemporâneo, sendo que obstaculizam o acesso do idoso vulnerável a este direito fundamental social.

Diante desta situação, a Constituição Federal de 1988 dispõe de instrumentos capazes de garantir a (re)afirmação do direito fundamental social do idoso ao benefício assistencial, dentre os quais destaca-se o papel da jurisdição democrática, tendo em vista que à luz do paradigma constitucionalista, as decisões jurisdicionais têm como pressuposto a materialização dos direitos fundamentais.

Segundo Streck (2003, p. 261), “A noção de Estado Democrático de Direito está, pois, indissociavelmente ligada à realização dos direitos fundamentais sociais. É desse liame indissolúvel que exsurge aquilo que se pode denominar de plus normativo do Estado Democrático de Direito".

Para Streck (2003, p. 261), “A essa noção de Estado se acopla o conteúdo material das constituições, através dos valores substantivos que apontam para uma mudança do status quo da sociedade".

Conceitua Ferrajoli (2008, p. 32) que a constituição consiste precisamente neste sistema de regras, substanciais e formais, que tem como destinatários os próprios titulares do poder.

Conforme explica Atienza (CRUZ; ROESLER, 2007, p. 46) o paradigma constitucionalista "se caracteriza pelo papel fundamental atribuído à Constituição", isto se deve pelo fato de que "a validade das normas, em especial das normas legisladas, depende de sua adequação à Constituição, e não unicamente a critérios formais e procedimentais, se não também a critérios materiais".

Staffen e Langer (2011, p. 979) afirmam que “A positivação de direitos fundamentais no texto constitucional torna o Estado devedor de uma série de prestações, que justamente por estarem inseridas no ordenamento jurídico, tornam-se judicialmente exigíveis". Sendo assim, "há que se reconhecer que o Poder Judiciário não pode manter-se inerte, ou mesmo afastado das questões sociais".

No Estado Democrático de Direito, “o polo de tensão, em determinadas circunstâncias previstas nos textos constitucionais, passa para o Poder Judiciário ou os Tribunais Constitucionais" (STRECK, 2003, p. 267). 
Considera-se a força normativa da Constituição como sendo capaz de contaminar todo o sistema jurídico, sendo que "todas as normas "textos" infraconstitucionais, para terem validade, devem passar, necessariamente, pelo processo de contaminação constitucional" (STRECK, 2014, p. 348).

Portanto, "a interpretação conforme a Constituição é mais do que princípio, é um princípio imanente da Constituição, até porque não há nada mais imanente a uma Constituição do que a obrigação de que todos os textos normativos sejam interpretados de acordo com ela" (STRECK, 2014, p. 351).

Além disso, a interpretação conforme a Constituição possibilita o combate às decisões das maiorias, que muitas vezes tentam suprimir os direitos fundamentais sociais já conquistados pelas minorias, o que caracteriza a denominada democracia constitucional, na qual o núcleo de proteção são os direitos fundamentais das pessoas mais fragilizadas.

A omissão ou inadequação do Estado na concretização dos direitos fundamentais sociais é um problema que ainda prevalece, o que faz do processo jurisdicional o foco para a efetivação destes direitos, tendo em vista que as políticas públicas não têm sido implementadas de maneira que garanta às pessoas vulneráveis o direito à igualdade e à dignidade humana9 .

Neste contexto, Streck (2014, p. 353) ao refletir sobre papel do processo no Estado Democrático de Direito, e juntamente com André Cordeiro Leal, afirma que:

[...] a jurisdição, a partir das propostas científicas de um processo a ser tematizado no Estado Democrático de Direito, não mais pode ser considerada atividade do juiz ou da magistratura em dizer o direito, mas, sim, o resultado da interpretação compartilhada do texto legal pelo procedimento regido pela principiologia constitucional do processo (contraditório, ampla defesa e isonomia) - principiologia esta que se apresenta exatamente como viabilizadora da clarificação discursiva de conteúdos fático-normativos pelos destinatários da decisão.

Em um contexto no qual o constitucionalismo tem se firmado como paradigma para a atuação dos Poderes Públicos, em especial para as decisões proferidas pelo Poder Judiciário, o qual está atrelado à efetiva concretização dos direitos fundamentais, evidencia-se a necessidade de uma jurisdição democrática, comprometida com o acesso à justiça tanto em seu aspecto formal como material. Segundo Staffen e Langer (2011, p. 983):

\footnotetext{
9 “Cappelletti já de há muito sustentava que o Poder Judiciário pode contribuir para o aumento da capacidade de incorporação do sistema político, garantindo a grupos marginais, destituídos dos meios para acessar os poderes políticos, uma oportunidade para a vocalização das suas expectativas e direito no processo judicial”. (STRECK, 2003, p. 269)
} 
O termo jurisdição democrática está ligado com o compromisso do poder judiciário em solucionar adequadamente os novos conflitos de ordem nitidamente sociais que chegam aos fóruns. São demandas que exprimem as tensões existentes na sociedade moderna, e que demandam julgamentos com viés nitidamente político e social.

No mesmo sentido, Abreu (2011, p. 266-267) explica que:

[...] o constitucionalismo democrático conduz a uma crescente expansão do âmbito de intervenção do Judiciário sobre as decisões dos demais Poderes. Com isso, põe-se em evidência o novo papel do Poder Judiciário na vida coletiva, justificando o manejo da expressão 'democracia jurisdicional'.

A jurisdição democrática é um importante instrumento para a concretização do direito do idoso ao benefício assistencial, tendo em vista que tem como pressuposto o acesso à justiça em seu sentido formal e substancial.

Boaventura de Sousa Santos (1999, p. 167) acentua que o tema do acesso à justiça "é aquele que mais diretamente equaciona as relações entre o processo civil e a justiça social, entre igualdade jurídico-formal e desigualdade socioeconômica".

Cappelletti (1988, p. 8) afirma que "o acesso à justiça pode, portanto, ser encarado como o requisito fundamental - o mais básico dos direitos humanos - de um sistema jurídico moderno e igualitário que pretenda garantir, e não apenas proclamar os direitos de todos".

É possível verificar a importância da jurisdição democrática na decisão proferida pelo Supremo Tribunal Federal na Reclamação 4374, na qual, por maioria, foi declarada a inconstitucionalidade do $\S 3^{\circ}$, do artigo 20, da Lei Orgânica da Assistência Social no julgamento da Reclamação 4374.

Segundo o voto do Ministro Relator Gilmar Mendes, o critério objetivo para aferir a miserabilidade do idoso é defasado, tendo em vista que o próprio legislador já considerou critérios mais brandos para concessão de benefícios de natureza assistencial ao editar leis mais recentes que regem programas de assistência social. Não obstante, tal critério não atende efetivamente ao comando constitucional proferido pelo artigo 203, inciso V, da Constituição Federal de 1988.

Fato este que enseja uma interpretação adequada do dispositivo legal, conforme a realidade socioeconômica do idoso, e em sintonia com os preceitos fundamentais da Carta 
Constitucional. Exige-se, portanto, uma análise de acordo com as especificidades de cada caso que é apresentado ao Poder Judiciário.

Quanto ao disposto no parágrafo único, do artigo 34, do Estatuto do Idoso, o Supremo Tribunal Federal, por maioria, negou provimento ao Recurso Extraordinário 580963, interposto pelo Instituto Nacional do Seguro Social, e declarou incidenter tantum a inconstitucionalidade do parágrafo único do artigo 34 da Lei no 10.741/03 (Estatuto do idoso). Porém, não foi atingido o quorum de $2 / 3$ para a modulação dos efeitos da decisão para que o referido dispositivo legal tivesse validade até 31 de dezembro de 2015.

Esta situação não impede que os magistrados continuem aplicando o parágrafo único do artigo 34 do Estatuto do Idoso, como por exemplo, nos casos em que um portador de necessidades especiais recebe o benefício assistencial, e um idoso integrante do grupo familiar pleiteia o mesmo benefício, ou no caso de um casal de idosos em situação de miserabilidade em que um percebe benefício previdenciário de valor mínimo. Assim, além de decidir com equidade, os magistrados estarão aplicando o princípio constitucional da igualdade, o qual não foi vislumbrado pelo legislador no momento da elaboração da regra.

Portanto, caracteriza-se a imprescindibilidade da jurisdição democrática como um importante instrumento para a (re)afirmação do direito fundamental social do idoso ao benefício assistencial, eis que se trata de uma justiça aperfeiçoada, que busca a consecução da igualdade e a concretização dos direitos fundamentais. Isto se dá devido à missão do Poder Judiciário de garantir e efetivar os direitos fundamentais na atual quadra da história, sempre colocando em prática o acesso à justiça e o exercício de uma hermenêutica constitucional que realmente alcance os objetivos de um Estado Democrático de Direito.

\section{CONSIDERAÇÕES FINAIS}

A evolução dos direitos fundamentais acontece historicamente, sendo que somente pode se falar em direitos fundamentais a partir do trânsito à modernidade. $\mathrm{O}$ processo de generalização dos direitos fundamentais é que traz à tona os direitos sociais como forma de alcance da igualdade, e formação do Estado Social, no qual se pretende instituir um patamar digno de vida para as pessoas vulneráveis. 
O Constitucionalismo Contemporâneo reconhece os direitos sociais como direitos fundamentais, e avança na medida em que estabelece garantias capazes de efetivar estes direitos.

A Constituição Federal de 1988 dispõe de um vasto catálogo de direitos e garantias fundamentais, além daqueles que prevê no decorrer do texto constitucional, dentre tais direitos estão consagrados os direitos fundamentais sociais, os quais demandam, além de uma atuação positiva do Estado para a sua concretização, uma abstenção, tendo em vista que caso haja o avanço de um direito fundamental social seja no plano normativo ou na prática social, este não pode ser objeto de retrocesso.

Considerando que o direito fundamental social do idoso ao benefício assistencial tem como objetivo proporcionar condições mínimas para que a pessoa idosa que não possui meios para prover sua subsistência atinja um patamar digno de vida, constata-se que não é possível a aplicação de critérios para a concessão deste benefício que o tornem inatingível.

Portanto, como o Poder Legislativo ainda não tomou nenhuma providência quanto à elaboração de critérios para a concessão do benefício assistencial ao idoso que atendam à realidade social e à dignidade humana, e que visem a assistência à pessoa idosa que se encontra em situação de vulnerabilidade, faz-se necessário o exercício de uma jurisdição democrática, pautada pelo paradigma do constitucionalismo, no qual a Constituição é o documento principal que orienta a tomada de decisões com o objetivo de que se concretizem os direitos fundamentais, com forte respaldo no acesso à justiça em sua dimensão formal e substancial.

Somente desta forma será possível garantir ao idoso a atenção especial que a Constituição Federal de 1988 estabelece, principalmente no que se refere ao dever de assistência à pessoa idosa e à sua dignidade humana.

A fixação dos critérios para a concessão do benefício assistencial não pode ser algo que obstaculize o acesso do idoso a este direito. A previsão legal de que a renda per capita do grupo familiar não pode ultrapassar um quarto do salário mínimo, e também que somente será excluído do cálculo da renda per capita o benefício assistencial recebido por outro membro do grupo familiar, não permitindo que outro benefício previdenciário de valor mínimo seja excluído do cálculo não podem prevalecer diante de sua inconstitucionalidade.

Sendo assim, o Poder Judiciário, através da tutela jurisdicional tem a possibilidade de verificar se no caso concreto o idoso realmente necessita do benefício assistencial, ainda que tais critérios não sejam cumpridos, pois o Instituto Nacional do Seguro Social, atuando 
consoante o princípio da legalidade, não deixará de aplica-los até que o Poder Legislativo elabora uma nova regra para a concessão do benefício.

Diante desta situação, conclui-se que e o acesso à justiça se perfaz diante de uma jurisdição democrática, tendo em vista a declaração de inconstitucionalidade dos requisitos, e a omissão do legislativo quanto à elaboração de novas regras para regulamentar o benefício assistencial.

Sendo assim, constatou-se que a jurisdição democrática é um importante instrumento de (re)afirmação do direito fundamental social do idoso ao benefício assistencial, pois é baseada nos ideais de igualdade e de acesso à justiça em seu sentido formal e substancial, permitindo que as decisões jurisdicionais sejam construídas de forma mais próxima e justa, principalmente nos casos em que se trata da proteção assistencial do idoso vulnerável.

\section{REFERÊNCIAS DAS FONTES CITADAS}

ABREU, Pedro Manoel. Processo e democracia: o processo jurisdicional como um locus da democracia participativa e da cidadania inclusiva no estado democrático de direito. São Paulo: Conceito Editorial, 2011.

BRASIL. Constituição da República Federativa do Brasil de 1988. Diário Oficial da União, n. 191-A, 05 out. $1988 . \quad$ Disponível em: http://www.planalto.gov.br/ccivil_03/Constituicao/Constituicao.htm Acesso em: 16 Fev. 2013.

Supremo Tribunal Federal. Reclamação 4374. Rel. Min. Gilmar Mendes. Disponível em: http://www.stf.jus.br/arquivo/cms/noticiaNoticiaStf/anexo/RCL4374.pdf Acesso em: 15 fev. 2016.

CASTRO, Carlos Alberto Pereira de; LAZZARI, João Batista. Manual de Direito Previdenciário. 14. ed. Florianópolis: Conceito Editorial, 2012.

CANOTILHO, J. J. Gomes. Direito Constitucional. 6. ed. Coimbra: Almedina, 1995.

CAPPELLETI, Mauro; GARTH, Bryan. Acesso à justiça. Porto Alegre: Fabris, 1988.

CARBONELL, Miguel; SALAZAR, Pedro. Garantismo: estudos sobre o pensamento jurídico de Luigi Ferrajoli. Madrid: Trotta, 2005.

CRUZ, Paulo Márcio. Política, poder, ideologia e estado contemporâneo. 3. ed. Curitiba: Juruá, 2003. 
CRUZ, Paulo Márcio; ROESLER, Claudia Rosane (Orgs.). Direito e argumentação no pensamento de Manuel Atienza. Rio de Janeiro: Lumen Juris, 2007.

FERRAJOLI, Luigi. Democracia y garantismo. Tradução de Perfecto A. Ibáñes, et al. Madrid: Trotta, 2010.

GARCIA, Marcos Leite. Efetividade dos Direitos Fundamentais: notas a partir da visão integral do conceito segundo Gregorio Peces-Barba. In: VALE, Juliano Keller do; MARCELINO

JUNIOR, Júlio Cesar. (Org.). Reflexões da Pós-Modernidade: Estado, Direito e Constituição. Florianópolis: Conceito, 2008.

MARTÍNEZ, Gregorio Peces-Barba. La diacronía del fundamento y del concepto de los Derechos: el tempo de la historia. In: MARTÍNEZ, Gregorio Peces-Barba. Curso de los Derechos Fundamentales: teoria general. Madrid: Universidad Carlos III de Madrid, 1995.

PISARELLO, Gerardo. Los derechos sociales y sus garantias: elementos para una reconstrucción. Madrid: Editorial Trotta, 2007.

SANCTIS JUNIOR, Rubens José Kirk. A polêmica envolvendo o conceito de miserabilidade para a concessão do benefício de amparo assistencial (LOAS). Revista Âmbito Jurídico. Previdenciário. Ano XIV, $\mathrm{n}^{\circ}$ 95, dez. 2011. Disponível em: http://www.ambitojuridico.com.br/site/?n_link=revista_artigos_leitura\&artigo_id=10897\&revista_caderno=20 Acesso em: 16 fev. 2016.

SANTOS, Boaventura de Sousa. Pela mão de Alice: o social e o político na pós-modernidade. São Paulo: Cortez, 1999.

STRECK. Lenio Luiz. Hermenêutica jurídica (e)m crise: uma exploração hermenêutica da construção do direito. Porto Alegre: Livraria do Advogado, 2014.

. Jurisdição constitucional e hermenêutica: perspectivas e possibilidades de concretização dos direitos fundamentais sociais no Brasil. Revista Novos Estudos Jurídicos, Vol. 8, n. 2, p. 257-301, maio/ago. 2003. Disponível em: <http://siaiap32.univali.br/seer/index.php/nej/article/view/336/280> Acesso em: 10 fev. 2016.

STAFFEN, Márcio Ricardo; LANGER, Octaviano. Considerações sobre a exigibilidade judicial dos direitos sociais em um estado democrático de direito. Revista Eletrônica Direito e Política, v.6, n.3, $3^{\circ}$ quadrimestre de 2011. Disponível em: 〈www.univali.br/direitoepolitica> Acesso em: 05 abr. 2016.

UVO, Roberta Terezinha. A concessão do benefício de prestação continuada. Portal do Envelhecimento. <http://www.portaldoenvelhecimento.org.br/acervo/artieop/Geral/artigo279.htm> Acesso em: 
13 fev. 2016.

WOLKMER, Antonio Carlos. Ideologia, estado e direito. 4. ed. São Paulo: Revista dos Tribunais, 2003. 